\title{
LIGHTNING STRIKE PROTECTION OF AIRCRAFT COMPOSITE STRUCTURES: ANALYSIS AND COMPARATIVE STUDY
}

\author{
Andrzej Katunin \\ Institute of Fundamentals of Machinery Design, Silesian University of Technology, \\ Konarskiego 18A, 44-100 Gliwice, Poland \\ andrzej.katunin@polsl.pl
}

\begin{abstract}
Lightning strikes are a serious problem during operation of aircraft due to the increasing applicability of polymeric composites in aircraft structures and the weak electrical conducting properties of such structures. In composite structures, lightning strikes may cause extended damage sites which require to be appropriately maintained and repaired leading to increased operational costs. In order to overcome this problem various lightning strike protection solutions have been developed. Some of them are based on the immersion of metallic elements and particles while others use novel solutions such as intrinsically conductive polymers or other types of highly conductive particles including carbon nanotubes and graphene. The concept of fully organic electrically conductive composites based on intrinsically conductive polymers is currently being developed at the Silesian University of Technology. The results obtained in numerous tests, including concerning electrical conductivity and the capability to carry on high-magnitude electrical charges as well as certain operating properties need to be compared with existing solutions in lightning strike protection of aircraft. The following study presents the properties of the material developed for lightning strike protection and a comparative study with other solutions.
\end{abstract}

Keywords: lightning strike protection, conductive composite, aircraft structures.

\section{INTRODUCTION}

Changes occurring over the last decades in design philosophy of many aircraft structures, in particular the application of fibre-reinforced composites with a polymeric matrix in the exterior fuselage, allowed the strength-to-mass ratio to be significantly increased, which resulted in the possibility of achieving higher speeds and manoeuvrability while keeping fuel consumption at a lower level. However, the usage of polymeric composites in manufacturing aircraft structures resulted in one drawback with respect to the lightning phenomena. Since polymers applied are dielectrics, the lightning strike events occurring during aircraft operation cause serious damage to such structures. This, in turn, requires expensive repairing and testing, and obviously, grounding the aircraft for the period of up to 6 working days [1], leading to increased operational costs.

A lightning striking a structure made of polymeric composite initiates numerous accompanying phenomena, which additionally intensify structural degradation and disintegration. Lightning strikes usually occur during take-off and landing of an aircraft as well as during passing through the storm clouds [2]. Lightning usually strikes a geometrically extremal point of an aircraft (like radome, wing tips, etc.) and travels through the structure along the shortest path, which is additionally the most conductive one, to exit at another geometrically extremal point [3]. During 
this process several accompanying phenomena occur. A high electrical discharge causes that almost insulating air becomes plasma with a very good conducting ability, and in the resulting lightning channel the temperature rapidly rises (locally even up to $30000 \mathrm{~K}$ ) [4]. The most influencing phenomena accompanied such an event are overpressure and resistive heating. The first one results from the appearance of an acoustic wave (when air fills the empty lightning channel) which interacts mechanically with a stroked structure and causes the external layers of the composite structure to break down and a net of cracks and delaminations to appear in the vicinity of the stroked area. This process is additionally intensified by a heat resulting from the fact that the composite structure acts as an electrical insulator. The giant discharge partially dissipates in the form of heat, reaching, in the most extremal cases, the temperature of up to several thousands of centigrades [5]. The resulting heat flux initiates pyrolytic processes such as local decomposition and vaporization of the polymeric matrix as well the ablation of the reinforcement, and even the ignition of the structure [6,7].

In order to overcome the problems caused by lightning strikes affecting composite elements, various lightning strike protection (LSP) solutions have been developed over the last decades. From a variety of LSP solutions one can mention several groups: coatings of metallized sprays or paints, impregnation of metallic meshes and foils as well as solutions based on dispersion of metallic particles, graphite and carbon nanostructures. Detailed overviews of these solutions can be found in [8-10]. An alternative approach to LSP of composite structures has been recently developed at the Silesian University of Technology. The approach developed utilises intrinsically conductive polymers (ICPs) as a conductive filler of a carbon fibre-reinforced polymeric (CFRP) structure. In order to evaluate the effectiveness of this material, it is necessary to compare the novel and existing LSP solutions. The comparison of electrical and mechanical properties of such solutions as well as processibility of components, manufacturing complexity and operability in conditions typical to the aircraft ground and in-flight cycles is the main goal of the presented study. Additionally, the analysis of aerospace standards and requirements regarding LSP systems was performed with a special focus on the properties of the material developed. The results obtained to date allow considering the developed LSP solution as a promising alternative to the currently applied solutions.

\section{ORGANIC CONDUCTIVE COMPOSITE}

The idea of development of a fully organic conductive composite resulted from analysis of existing LSP solutions, both the ones currently applied (e.g. expanded metallic meshes and foils in the newest passenger aircraft, namely Boeing ${ }^{\circledR} 787$ Dreamliner and Airbus ${ }^{\circledR}$ A350 XWB) as well as prototypical ones (e.g. polymeric composites with metallized reinforcing fibres, dispersed metallic and non-metallic particles). The results of the analysis [10] show that the existing solutions have several drawbacks, e.g. the LSP solutions based on the impregnation of metallic meshes and foils, despite their high effectiveness in LSP, significantly complicate the manufacturing process of such composite structures, and, additionally, increase the mass of an aircraft as the whole fuselage should be covered with a metallic mesh or foil. Moreover, due to generally low adhesion on the metal-polymer interface, debonding may occur leading to internal structural damage. If structural damage appears, the interaction of the metallic mesh with the environment may initiate corrosion processes in metallic inserts leading to the propagation of the existing damage. Other LSP solutions used today, such as metallized paints and sprays for covering composite structures, are usually not effective in the case of high current discharges due to low thickness of the coating and a low content of conducting particles incapable of forming conducting paths properly. The novel solutions developed over the last decade, have sometimes purely scientific meaning (e.g. solutions that rely on dispersion of carbon nanotubes) since the manufacturing costs of such structures are too high to apply them in practice. 
In view of the above and to avoid the mentioned drawbacks of various LSP solutions, the following assumptions were considered during the development of the organic composite:

- the material should not contain any metallic inserts in order to avoid weak adhesion on the metal-polymer interface and hold a structure lightweightness,

- in order to hold the lightweightness a conductive filler from a group of ICPs should be chosen,

- selected ICP should be widely available and should be characterized by a simple and lowcost synthesis process,

- the content of ICP conducting particles should reach a compromise between mechanical and electrical properties so that the resulting material is characterized by good electrical and mechanical properties,

- the manufacturing process should be low-cost if a conductive composite structure is to be a substitute for currently used LSP solutions.

The organic composite was manufactured in compliance with the above considerations from epoxy resin (due to its good mechanical properties and a wide applicability for manufacturing in aircraft composite structures) and polyaniline (PANI), an ICP which fulfils all the mentioned requirements and is characterized by conductivity on the level of semiconductors, which consists of a matrix of a composite structure with additional dopants, solvents, hardeners, etc. (see $[11,12]$ for details). The content of PANI was assumed based on numerical simulations using the percolation theory [13] as well as conducted during the manufacturing of specimens [12]. In order to obtain the required mechanical strength and stiffness a carbon fibre reinforcement was impregnated into the obtained polymeric mixture. The presence of carbon fibre (fabric, cloth) plays an additional role: the conducting paths in the material resulting from a formed percolation cluster were additionally supported by the impregnated fibre which also has an ability of conducting electrical current.

\section{REQUIREMENTS FOR LSP SOLUTIONS AND COMPARATIVE STUDIES}

The most specific recommendations regarding LSP are given by the Society of Automotive Engineers (SAE) aerospace recommended practices (ARP) and several U.S. military standards (MIL-STD). The two main industrial recommendations are SAE ARP 5412A [14] and SAE ARP 5414A [15]. These recommendations are used as the basis for U.S. Federal Regulations applicable worldwide. The second of the mentioned SAE ARPs defines specific zones of lightning strikes on a typical strait-wing jet aircraft. To each of the 6 defined zones, a specific lightning current waveform is attributed (defined in the first one of the mentioned industrial recommendations). The highest current values (up to $200 \mathrm{kA}$ ) are attributed only to small areas, namely the nose, wings and stabilizers tips and the front parts of turbine housings, while the most of the fuselage belongs to the second zone, where the current values are much lower (up to $2 \mathrm{kA}$ ). Following this, LSP solutions can be applied locally depending on a specific lightning zone. In consideration of the above recommendations as well as additional recommendations related to testing and certification of lightning effects [16-18], aircraft manufacturing companies develop their own LSP controlling systems [1] and testing procedures [6] applied after the lightning strike event. Those should comply with the following U.S. Federal Regulation procedures [19]:

- Systems Lightning Protection - 14 CFR 25.1316, which encompasses both direct effects and indirect effects of a lightning strike,

- Fuel Systems Lightning Protection - 14 CFR 25.954 and 25.981, which also includes direct and indirect effects,

- Lightning Protection - 14 CFR 25.581, which includes lightning direct effects,

- Precipitation Static - 14 CFR 25.899(a)(3). 
In Europe, these regulations were standardized by the European Organization for Civil Aviation Electronics. An overview of the EUROCAE standards related to the mentioned SAE ARPs can be found in [20]. The mentioned documents, however, do not provide any requirements related to materials and their properties. However, the higher conductivity of a stroked structure is the less extensive damage appears. Following internal regulations of aircraft manufacturers, defined similarly to the foreign object damage (FOD) maintenance and inspection procedures, where the threshold is determined by barely visible impact damage (BVID) and visible impact damage (VID), characteristic thresholds for lightning strike events were determined [21]. These regulations and statistical data indicate that the lightning current discharges in the range of 5-10 kA are the most common.

In order to perform qualitative evaluation of the properties of the newly developed composite material and its adequacy to applicable standards and requirements it was necessary to compare this material and other LSP solutions using the following criteria: electrical $\lambda$ and thermal $\sigma$ conductivity, density $\rho$, ultimate tensile strength UTS, complexity of a manufacturing technology, and costs of a given LSP solution. Table 1 presents the materials used in LSP solutions and their physical properties important for LSP of aircraft structures, while Table 2 presents the analysis of manufacturing technologies, related costs and effectiveness of selected LSP solutions. Note that values in Table 1 should be considered as indicative only.

Table 1. Comparison of properties of materials used in LSP solutions [5,9,22-26]

\begin{tabular}{|c|c|c|c|c|}
\hline Material & $\lambda, \mathrm{S} / \mathrm{m}$ & $\sigma, \mathrm{W} / \mathrm{m} \cdot \mathrm{K}$ & $\rho, \mathrm{kg} / \mathrm{m}^{3}$ & $U T S, \mathrm{MPa}$ \\
\hline Aluminium & 38200000 & 205 & 2690 & 110 \\
\hline Copper & 59800000 & 401 & 8930 & 220 \\
\hline Graphite & 72700 & 168 & 2250 & $24-110$ \\
\hline CFRP & 29.3 & 11.8 & 1520 & $350-600$ \\
\hline CNT-reinforced composite & 100000 & $0.2-0.25$ & 1400 & 1200 \\
\hline Composite with metallized fibre & $750-10000$ & 414 & $2400-5100$ & 650 \\
\hline ICP-based composite & $100-50000$ & 10.9 & 1521 & $300-800$ \\
\hline
\end{tabular}

Table 2. Manufacturing technologies and costs

\begin{tabular}{|c|c|c|c|}
\hline LSP solution & Manufacturing technology & $\begin{array}{c}\text { Costs of } \\
\text { LSP }\end{array}$ & $\begin{array}{c}\text { Effectiveness } \\
\text { of LSP }\end{array}$ \\
\hline Highly conductive metal coatings & $\begin{array}{c}\text { Simple (metallized paints or } \\
\text { sprays) }\end{array}$ & Low & Low \\
\hline CFRP structure & $\begin{array}{c}\text { Standard manufacturing } \\
\text { process }\end{array}$ & Low & Very low \\
\hline CNT-reinforced composite & $\begin{array}{c}\text { Simple (possible difficulties } \\
\text { with dispersion of CNTs) }\end{array}$ & $\begin{array}{c}\text { Very } \\
\text { high }\end{array}$ & Excellent \\
\hline $\begin{array}{c}\text { Composite with metallized fibre or } \\
\text { immersed metallic meshes/foils }\end{array}$ & $\begin{array}{c}\text { Complicated (fibre } \\
\text { polymer adhesion) }\end{array}$ & High & Fine \\
\hline ICP-based composite & $\begin{array}{c}\text { Simple (possible difficulties } \\
\text { with dispersion of CNTs) }\end{array}$ & Medium & Fine \\
\hline
\end{tabular}

Although CNT-reinforced composites have excellent properties with reference to LSP and require a simple manufacturing technology, the costs of materials are too high to apply them in LSP on an industrial scale. Further analysis of the results presented above shows that the proposed LSP solution (ICP-based composites) have physical properties comparable with those of composites with metallized fibre of immersed metallic meshes or foils, but have, due to their 
organic nature, significantly lower density and require anmuch simpler manufacturing technology. Following the performed analyses and regulations of LSP, the developed organic conductive composite can be considered in future as an appropriate candidate for alternative LSP solution to be used in aircraft structures.

\section{SUMMARY}

This study focused on the comparative analysis of physical properties and manufacturing technologies of various LSP solutions, including the developed organic electrically conductive composite in the light of technical and economical effectiveness of their applicability in protection of aircraft structures. The analysed regulations and standards as well as comparative studies show that the developed composite can be considered as a promising candidate for a LSP solution for aircraft structures due to its good strength-to-mass ratio, acceptable electrical and thermal conductivity and low-cost manufacturing process. Further studies will be focused on improvement of physical and processing parameters of the developed composite.

\section{REFERENCES}

[1] Forget F., Ground lightning protection. An adapter for Ground Power Units, Airbus Technical Magazine, 53, 4-9, 2014.

[2] Mall S., Ouper B.L., Fielding J.C., Compression strength degradation of nanocomposites after lightning strike, Journal of Composite Materials, 43, 2987-3001, 2009.

[3] Gou J., Tang Y., Liang F., Zhao Z., Firsich D., Fielding J., Carbon nanofiber paper for lightning strike protection of composite materials, Composites Part B: Engineering, 41(2), 192-198, 2010.

[4] Abdeal G., Murphy A., Nonlinear numerical modelling of lightning strike effect on composite panels with temperature dependent materials properties, Composite Structures, 109, 268-278, 2014.

[5] Katunin A., Krukiewicz K., Preliminary analysis of thermal response of dielectric and conducting composite structures during lightning strike, Composites Theory and Practice, 16(1), 8-14, 2016.

[6] Sweers G., Birch B., Gokcen J., Lightning strikes: protection, inspection and repair, Aero Magazine, 4, 19-28, 2012.

[7] Chemartin L., Lalande P., Peyrou B., Chazottes A., Elias P.Q., Delalondre C., Cheron B.G., Lago F., Direct effects of lightning on aircraft structures: analysis of the thermal, electrical and mechanical constraints, Journal of Aerospace Lab, 5, AL05-09, 1-15, 2012.

[8] Rupke E.J., Lightning direct effects handbook, Lightning Technologies Inc., Pittsfield, MA, 2002.

[9] Gagné M., Therriault D., Lightning strike protection of composites, Progress in Aerospace Sciences, 64, 1-16, 2014.

[10] Katunin A., Krukiewicz K., Herega A., Catalanotti G., Concept of a conducting composite material for lightning strike protection, Advances in Materials Science, 16(2), 32-46, 2016.

[11] Krukiewicz K., Katunin A., The effect of reaction medium on the conductivity and morphology of polyaniline doped with camphorsulfonic acid, Synthetic Metals, 214, 45-49, 2016.

[12] Katunin A., Krukiewicz K., Turczyn R., Sul P., Łasica A., Bilewicz M., Synthesis and characterization of the electrically conductive polymeric composite for lightning strike protection of aircraft structures, Composite Structures, 159, 773-783, 2017. 
[13] Katunin A., Percolation thresholds of 3D all-sided percolation clusters in non-cubic domains, Journal of Applied Mathematics and Computational Mechanics, 15(4), 63-69, 2016.

[14] Society of Automotive Engineers. Aerospace recommended practice - 5412 Rev A: Aircraft Lightning Environment and Related Test Waveforms, SAE International Edition, 2005.

[15] Society of Automotive Engineers. Aerospace recommended practice - 5414 Rev A: Aircraft Lightning Zoning, SAE International Edition, 2005.

[16] Society of Automotive Engineers. Aerospace recommended practice - 5413: Certification of Aircraft Electrical/Electronic Systems for the Indirect Effects of Lightning, SAE International Edition, 1999.

[17] Society of Automotive Engineers. Aerospace recommended practice - 5577: Aircraft Lightning Direct Effects Certification, SAE International Edition, 2002.

[18] Society of Automotive Engineers. Aerospace recommended practice - 5416: Aircraft Lightning Test Methods, SAE International Edition, 2005.

[19] Fisher F.A., Plumer J.A., Lightning protection of aircraft, NASA Reference Publication 1008, General Electric Company, Pittsfield, MA, 1977.

[20] Morgan D., Hardwick C.J., Haigh S.J., Meakins A.J., The interation of lightning with aircraft and challenges of lightning testing, Journal of Aerospace Lab, 5, AL05-11, 1-10, 2012.

[21] Feraboli P., Miller M., Damage resistance and tolerance of carbon/epoxy composite coupons subjected to simulated lightning strike, Composites Part A: Applied Science and Manufacturing, 40(6-7), 954-967, 2009.

[22] Ranjith R., Myong R.S., Lee S., Computational investigation of lightning strike effects on aircraft components, International Journal of Aeronautical \& Space Sciences, 15, 44-53, 2014.

[23] Wang Z., Ciselli P., Peijs T., The extraordinary reinforcing efficiency of single-walled carbon nanotubes in oriented poly(vinyl alcohol) tapes, Nanotechnology, 18, 455709, 2007.

[24] Wang S., Liang R., Wang B., Zhang C., Dispersion and thermal conductivity of carbon nanotube composites, Carbon, 47(1), 53-57, 2009.

[25] Huang C.Y., Mo W.W., Roan M.L., Studies on the influence of double-layer electroless metal deposition on the electromagnetic interference shielding effectiveness of carbon fiber/ABS composites, Surface and Coatings Technology, 184(2-3), 163-169, 2004.

[26] Tao Z., Guo Q., Gao X., Liu L., Graphite fiber/copper composites with near-zero thermal expansion, Materials and Design, 33, 372-375, 2012. 